\title{
Analysis on Low-carbon Designing Orientation of Solving and Improve Living Environment for Low-income People
}

\author{
Dong Junyan $^{1,2,3, a}$, Cheng Wen ${ }^{1}$, Li Kechao ${ }^{2, b}$, Xing Yuenan ${ }^{2}$, Tan Tenglong ${ }^{2}$ \\ ${ }^{1}$ School of Architecture, Harbin Institute of Technology, Harbin, China \\ ${ }^{2}$ School of Architecture and Design, Changchun Institute of Technology, Changchun, China \\ ${ }^{3}$ International Asia Art Academy, Banggkok Thonburi University, Bangkok, Thailand \\ adjyrob@gmail.com, '93045611@qq.com
}

\begin{abstract}
Keywords: Low-carbon design, Low-income people, Living Environment
Abstract. In recent years, the environmental problems have been ceaselessly springing up and the low-carbon orientation has become the inevitable choice to tackle the environmental problems in the field of architecture. Under these circumstances, the construction of low-carbon salving architectures for low-income people boasts prominent social significance. This paper based on the development of theoretical consensus between low-carbon architecture and salvation for low-income people with the evidence of the designing examples of related architecture at home and abroad, provides the designing strategies for the development of low-carbon salving architecture for low-income people of China.
\end{abstract}

Since the 1960s, with the problems such as energy drain, climate anomaly and environmental deterioration etc constantly springing up, the cry for Eco-environmental protection has been on the up. Currently, the concept of sustainable development has penetrated into all the aspects in the field of architecture, giving impetus to the overall architectural development trend. Under such circumstances, many types of architecture have begun to adopt low-carbon designing, including the salving architecture for low-income people. As a characteristic architectural type, the salving architecture for low-income people is the site specifically provided for low-income people with protection in life and development. Developing salving architecture for low-income people in the low-carbon concept not only complies with the tendency of architectural development worldwide but also sublimes the protection of the salving architecture for low-income people up to the lofty love in the mortal world.

\section{Introduction}

By nature, the development of low-carbon architecture and salvation for low-income people boasts identical value orientation, that is to say, to pursue equality and efficiency.

Equality and efficiency constitute the core problems stressed by the development of low-carbon architecture. Since the mankind entered the industrial society, the industries in all the fields such as urban industrial production, processing and manufacturing and traffic building etc always burn or use one-off energy in large quantities, producing and discharging large amounts of carbon dioxide in this way and leading to the rapid warming of the climate environment on the earth. Thereupon, it may finally engender the repeated occurrence of disastrous climates and environmental changes, which will severely threaten the normal living environment of the mankind [1]. This makes people begin to realize that we the constructors of the planet should transfer the way to get along with the planet as the protectors instead of the squeezers[2]. Developing low-carbon architecture is the important way for the mankind to protect their own living space. This kind of protection is based on the necessities of the interests of the modern people instead of at the expense of sacrificing the interests of the following generations. It can be put in this way that low-carbon approach is the strategic method to equalize the interests of this and latter generations. In the same process of attaching emphasis to the issue of equality, the stress on efficiency is another feature to develop the low-carbon architecture. It is because that only through boosting the utilization ratio of resources and energy can effectively lower the discharge of carbon dioxide and achieve the goal to protect the living environment of the mankind. 
Consequently, considering from this angle, low-carbon is a strategic mode to stimulate development through efficiency.

Equality and efficiency are both the core issues of the interested salvation for low-income people. The rights to subsistence and development are the fundamental rights every citizen in the modern society should enjoy. Nevertheless for the low-income people, the street life frequently makes their rights to subsistence and development neglected or deprived. The shortage of materials in the process of wandering and mode of wandering exclude them from the normal association, practice and rights in the modern society [3]. The material assistance and various services the social salvation provides to the low-income people ensure the low-income people to enjoy the equal rights with other citizens. We can see that equality is the aim of social salvation. In the course of realizing this purpose, the resources and services got by the helped boast some values and even the values that can be directly measured by means of currency. Raising the efficiency of social salvation means to create more social benefits under the conditions without lowering input, which no doubt plays the function to maximize the target of equal social salvation.

The significance of the low-carbon development of salving architectures for low-income people lies in applying the methods of salving the natural environment of the mankind and their own fate to the activities of social salvation, sequentially breaking through the narrow scopes of social salvation for designated multitude and making the procedure of salving others a salvation for the mankind[4].

\section{Exploration of Practice}

Presently, the United States has developed the designing concept of low-carbon architecture to the designing of salving architecture for low-income people, setting a successful example to the growth of this type of architecture.

In the United States, the Boulder Shelter is the first salvation facility to realize the low-carbon designing concept(Fig 1). Built in 2013, the Boulder Shelter's facility at 4869 North Broadway was designed and built to minimize environmental impacts and operating costs.
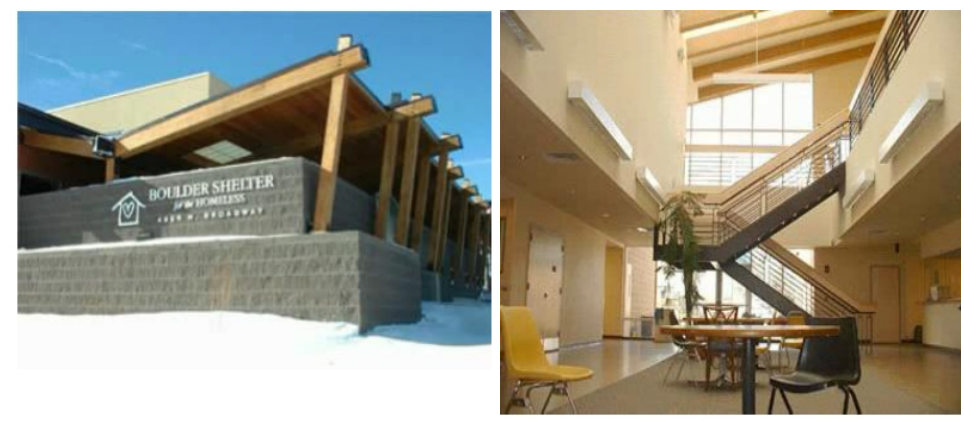

Figure 1. Boulder Shelter

The Austin Resources Center for the low-income established in 2004 is another salving facility based on the theory of low-carbon designing of the United States(figure 2).

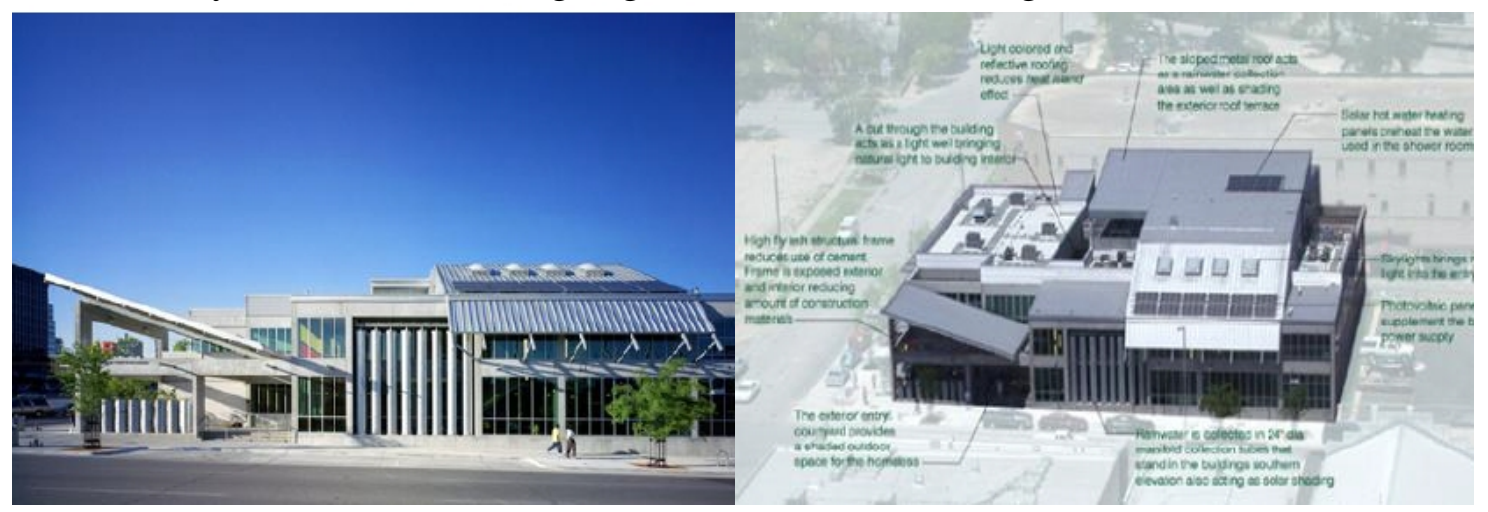

Figure 2. Austin resource center for the low-income 
The Center is expected to use $20 \%$ less energy than a conventional building. The building includes extensive daylight harvesting. Deep structural frames allow sunlight to enter the building during the winter, but not during the summer. The central light well, which is oriented along a north-south axis, allows a small portion of direct sunlight to enter the building while the majority is reflected from the metal-panel cladding glazing inside the light well. The third-floor roof terrace extends over a portion of the western flat roof, shading part of the roof area. The building's exposed concrete frame elements act as thermal mass, remaining cool during the early portion of the day and radiating heat in the evening. The project has a reflective roof coating (75\% reflection and 0.91 impassivity), lowering interior cooling loads and reducing the project's contribution to the urban heat-island effect. The refrigeration for the main building systems is free of both CFCs and HCFCs, reducing the potential to deplete the Earth's ozone layer[5]. The building includes 48 donated photostatic panels, which generate $0.43 \%$ of the building's electricity use. Solar hot-water panels preheat water for uses in the building. A 13,000-gallon rainwater-collection system reduces runoff from the site. Water from this system is used for all of the irrigation and as an alternate supply for flushing toilets and urinals. Using rainwater for flushing reduces the building's waste water generation by more than $50 \%$. Infrared sensors on the building's faucets limit water use, contributing to a 30\% reduction in indoor potable water use. This translates into approximately 600,000 gallons of water saved each year. This project was chosen as an AIA Committee on the Environment Green Project for 2015.

\section{Development Strategies}

The combination of development low-carbon architecture and the social salvation concept along with the practice of low-carbon salvation architecture established by the developed countries theoretically and practically prove that it is very adoptable and meanwhile very practical for the salving architecture for low-income people to take orientation of low-carbon development. The low-carbon designing orientation of the salving architecture for low-income people indicates to make the constructing activities more tally with the requirements of environmental protection through cutting the costs to support the architectural environment to create the healthy, comfortable and economic living environment for the low-income people. To achieve this designing target, the following strategies can be adopted:

First and foremost, establishing the awareness of low-carbon design of salving architecture in the pro-phase and attaching importance to cultivation of the low-carbon concept. The salving architecture for low-income people is the type of architecture to serve the underprivileged social multitude. Under the influence of cultural, economic and social factors etc, the development of this type is easily neglected, hence the phenomenon of lagging behind in the application of new technologies and new concepts. Although the low-carbon architecture has been no longer new in China, it is also the development orientation never experienced in the evolution of salving architecture for low-income people.

Sequentially, it should make efforts to strengthen the awareness of environmental protection and establish the low-carbon designing concept in designing salving architecture for low-income children.

In the next place, making use of space construction to cut building energy consumption. In the overall site arrangement, full consideration should be given to the factors such as the orientation, location, volume and patterns of the architecture with the aim to reduce environmental destruction and energy consumption in the course of coordinating architecture and the natural environment. As for the spacial arrangement, it should create the architectural space benefiting natural ventilation, lighting and view borrowing, for instance, arranging atrium or courtyard in reasonable sizes inside the buildings and bringing sunlight, air and greening to ameliorate and beautify the indoor environment. As for mould shaping, conditions such as the local climates, sunlight and wind direction etc should be combined for designing, thus forming the characteristic architectural mould adapting to the local environment and getting rid of the rigid mode of traditional salving architectures. 
Moreover encouraging the establishment of energy-saving and emission-cutting salving architecture through technique. In the practical construction and without added technology, the architectural design has found it difficult to meet the increasingly strict low-carbon code requirements at the prevailing stage. For this reason, importance should be attached to the research on development strategies of technology. This kind of development strategy requires that the architectural project should satisfy the demands of the society for basic comforts of the man-made environment such as wind, light and heat etc and the needs for special functional services and at the same time save resources (energy reduction, land reduction and materials reduction), protect the environment and cut the emission of greenhouse gases and solid castoff etc in the entire life cycle as much as possible with the purpose to adapt to the demand of the human society for sustainable development. In applying the specific technology and in accordance with the features of the salving architecture for low-income people, it should emphasize the new energy boasting low carbon and zero carbon such as wind energy, terrestrial heat and solar energy etc to regulate the indoor environment and provide the supplementing architectural energy to cut the operating costs of the architecture; it should stress the technology to make use of water resources recycling to gather rainwater or relatively clean living water for the links such as cleaning the washroom and greening etc to reduce the water volume in architecture and the generation volume of sewage; it should lay emphasis on the adoption of environment-friendly construction materials, thermal insulators and decorative materials to prevent hazardous chemicals from dispersing in the air and affecting the health of the users etc.

\section{Conclusions}

To sum up, the fact that the salving architecture for low-income people takes the route of low-carbon designing needs the overall endeavor in the concepts, designing and technology of construction. However, there is sharp gap of the research in this aspect which needs the participation and exploration of more experts and scholars of social responsibilities in the time ahead.

In the human society, low-income people comprise a disadvantaged multitude. Establishing salving architecture for low-income people reflects the love of the mainstream multitude of the society to the underprivileged. Confronted with the powerful nature, the mankind itself is a disadvantaged group of people. Developing low-carbon architecture is the necessary choice the mankind must make to protect the living environment of itself. Taking the orientation of low-carbon development, the salving architecture for low-income people displays the universal true feelings of the mankind.

\section{References}

[1] Junyan Dong, Hong Jin. The design strategy of green rural housing of Tibetan areas in Yunnan, China. Renewable Energy, Vol. 49, pp. 63-67.

[2] Junyan Dong, Wen Cheng. Based on the Characteristics of Respondents and the Voice of the Urban Neighborhood Public Space Business Facilities Noise Environment Evaluation Research. Journal of Harbin Institute of Technology.2014,20(4),pp.103-109.

[3] Junyan Dong, Hong Jin, Jian Kang, Xi Chen, A pilot study of the acoustic environment in residential areas in Harbin, towards the questionnaire design. Journal of Harbin Institute of Technology.2011,18(2),pp.319-322.

[4] Junyan Dong, Wen Cheng.Research on Optimized Construction of Sustainable Human Living Environment in Regions where People of a Certain Ethnic Group Live in Compact Communities in China.World Renewable Energy Congress XIV.2015.6

[5] Junyan Dong.The Acoustic Environment Research of Construction Exterior Based on the Ecology Idea. Materials Engineering and Environmental Science. 2015.9 